\title{
CLINICAL STUDIES ON THE RESPIRATION
}

\section{THE BASAL METABOLISM AND THE MINUTE-VOLUME OF THE RESPIRA-} TION OF PATIENTS WITH CARDIAC DISEASE *

FRANCIS W. PEABODY, M.D., JOHN A. WENTWORTH, M.D. AND

\author{
BERTHA I. BARKER \\ BOSTON
}

In a recent communication from the Russell Sage Institute of Pathology the first satisfactory observations on the basal metabolism of patients with heart disease were reported. Sixteen patients with cardiac or cardiorenal disease were studied in the bed calorimeter at Bellevue Hospital, New York. An important result of the investigation was the close agreement found in the determination of the metabolism by the direct and indirect methods of calorimetry. Such an agreement, together with the finding of normal respiratory quotients, makes it probable that the metabolism in heart disease is not of an essentially abnormal type, and justifies the use of the indirect method in future work. It was furthermore shown that in patients with compensated cardiac lesions the metabolism was within normal limits, while in patients who had dyspnea while at rest in bed the metabolism was either normal or increased. "Of twelve patients with dyspnea, nine showed a distinct rise in metabolism, and in five of these the increase was from $25 \%$ to $50 \%$ above the average normal."

The work reported in the present paper is in part a continuation of that done at the Russell Sage Institute, as it seemed worth while to secure more data on so important a subject as the basal metabolism in heart disease. In part, however, it is an extension, for the method used allowed us to obtain information concerning the pulmonary ventilation, and the minute-volume of air breathed. This was of considerable significance to us, since one of the primary reasons which led to the study of heart disease was an interest in the mechanism of the production of dyspnea. It will be readily seen that the minutevolume of air breathed is an important factor in the investigation of patients from this point of view. The greater the amount of air which a patient breathes while at rest, the more limited he will be in his ability

* Submitted for publication April 30, 1917.

* From the Medical Clinic of the Peter Bent Brigham Hospital, and the Medical School of Harvard University. 980 .

1. Peabody, Meyer and Du Bois: The Archives Inr. Med., 1916. 17, Part II, 
to increase his ventilation in response to the rising metabolism accompanying muscular exertion. Thus the greater will be his tendency to become dyspneic easily.

\section{METHOD}

The method used in the metabolism experiments was that of Tissot, the spirometer, valves and general technic being essentially as described by Carpenter. ${ }^{2}$ Instead of the nose pieces, however, a rubber mask. recommended by Carpenter and made by the Siebe-Gorman Company for their mine rescue apparatus was used. This proved to be a distinct advantage, for the subjects could breathe either through the mouth or nose according to their desire, and in getting reliable records of the minute-volume, it is, of course, essential that the respiration should be as natural as possible. In a few instances the mask could not be adjusted easily and a rubber mouth-piece was used, the nose being tightly clipped. The spirometer was of 100 liters capacity. The experimental periods were usually ten minutes long, but when the minute-volume was particularly high, they were necessarily of shorter duration. The inspired air was piped from outdoors to the inspiratory valves, so that there was no error, as might be the case if room air was used. The analyses of expired air were made with the Haldane portable gas analysis apparatus. ${ }^{3}$ The measured volume of expired air was reduced to standard conditions of temperature and barometric pressure, and the calculations were performed in the usual manner.

The metabolism as measured by the heat production in calories per hour was calculated from the oxygen consumption, use being made of the customary table which gives the calorific value of oxygen according to the respiratory quotient. The metabolism was then finally expressed in calories per square meter body surface per hour. The surface area was determined from the height and weight of the patient according to the chart of $\mathrm{Du}$ Bois and Du Bois. ${ }^{4}$ The average error of this simple method is +1.5 per cent., and the maximum error is only +5 per cent. Heat production varies of course normally, depending on the age and sex of the subject. The comparison of results in this series of observations has been somewhat simplified by the fact that all the subjects were males. For those between the ages of 20 and 50 years the normal standard of 39.7 calories per square meter of surface area, as given by Gephart and DuBois, ${ }^{5}$ has been assumed. For

2. Carpenter: A Comparison of Methods for Determining the Respiratory Exchange of Man, Pub. 216, Carnegie Institution of Washington, 1915. 1912.

3. Hâldane: Methods of Air Analysis, Charles Griffin \& Co., Limited, London,

4. Du Bois and Du Bois: The Archives Int. Med., 1916, 17, 863.

5. Gephart and DuBois: The Archives Int. Med., 1916, 17, 902. 
older or younger subjects the average normals given by $\mathrm{Du}$ Bois ${ }^{6}$ for the various ages have been used. In the tables the metabolism is expressed in the percentage of the appropriate normal.

The general method of conducting the observations was as follows: The patient was brought to the laboratory on the afternoon before the day of the actual experiment. He was then shown the apparatus, the mask was put on his face, and the various experimental manipulations were run through with. This was found to be extremely important, as the subjects were naturally somewhat excited and anxious about what was going to take place. This preliminary trial, however, accustomed them to the method and reassured them completely. On the following morning they were brought to the laboratory in their beds, having fasted since the previous evening. After quieting down for about one-half hour, a record of the normal respiration was taken with a pneumograph. The mask was then adjusted and the metabolism experiment begun. When possible, three continuous ten-minute periods were run, but some of the more sick patients became fatigued after two periods, so that it was necessary to stop the observation. Pnenmographic tracings were taken throughout each period, and the average rate of respiration counted. From the volume of expired air the average volume per single respiration was then calculated. The heart rate was counted, without the knowledge of the patient, by means of a stethoscope attached over the precordia.

The clinical condition of the patients on whom this report is based varied greatly. Some had slight valvular lesions, but were otherwise perfectly well, and had no evidence of cardiac decompensation. Others were seriously sick, and suffered from dyspnea and orthopnea. All were propped up in a semireclining position on bed-rests during the observation, but it has been shown that the metabolism is only about 3 per cent. lower in this posture than when lying flat on the back. ${ }^{7}$ It is obvious that it is extremely difficult to study the ventilation and the metabolism of patients who are dyspneic or who have a tendency to dyspnea. They are often easily worried by anything like a mask over the mouth or nose, and the psychic condition may alter the type of respiration profoundly. Many patients are wholly unsuitabie to work with. The ones reported here are practically picked patients who were intelligent and anxious to cooperate with the work. We can feel reasonably certain that the results indicate the natural conditions.

In a former paper ${ }^{8}$ it has been shown that there is a close relationship between the tendency to dyspnea in cardiac patients and the vital

6. Du Bois: The Archives Int. Med., 1916, 17, 887.

7. Soderstrom, Meyer and Du Bois: The Archives Int. Med., 1916, 17, 872.

8. Peabody and Wentworth: See page 443 , this issue. 
capacity of the lungs. This is apparently so generally true that in those cases in which dyspnea is the predominating symptom - and this includes the majority of persons with heart disease - the vital capacity is a peculiarly accurate index of the clinical condition. Patients with a high vital capacity have little or no disturbance from dyspnea, while those in whom the vital capacity is below normal suffer from shortness of breath, and the degree to which they suffer depends largely on the decrease in vital capacity of the lungs. On this basis, then, it has seemed to be of interest in the present study to divide the patients into two groups according to the vital capacity. The first group consists of ten subjects with a vital capacity over 60 per cent. of the normal, according to the standards established by us. The mem. bers of this group were in comparatively good clinical condition, all of them being comfortable while at rest, and those whose vital capacity approached normal having little or no dyspnea even with moderate exercise. The second group consists of fourteen patients in whom the vital capacity was 60 per cent. of the normal or less. These were for the most part severely affected persons. Almost all of them became dyspneic on slight exertion, and those whose vital capacity was lowest tended to be dyspneic even while at complete rest in bed. It will be noted in the table that the average size of the patients in the two groups, as measured by their body surface area, is approximately the same.

\section{RESULTS}

The essential features of the various observations are shown in detail in the table. It is scarcely necessary to go into a discussion of the individual cases, as a consideration of the average findings in each group brings out clearly the more important results, and there are few significant deviations from the average.

Expired Air.-Analysis of the expired air shows that in Group I the percentage of carbon dioxid is higher and the percentage of oxygen is lower than in Group II. In Group I the carbon dioxid averaged 3.35 per cent. and the oxygen 17.04 per cent., while in Group II the carbon dioxid averaged 2.44 per cent. and the oxygen : 18 per cent. Thus in the more severely affected patients the expired air approaches closer to the composition of atmospheric air, and one may say that the inspired air is less effectively used than normally. This is in harmony with the observations of Siebeck, ${ }^{9}$ who found that when cardiac patients were made to inspire pure hydrogen, the expired air in the dyspneic, decompensated cases contained a higher percentage of the inspired hydrogen than it did in normal persons or in compensated cardiac cases.

9. Siebeck: Deutsch. Arch. f. klin. Med., 1912, 17, 252. 
Basal Metabolism

\begin{tabular}{|c|c|c|c|c|c|c|c|c|c|c|c|c|}
\hline \multirow{2}{*}{$\begin{array}{c}\text { Case } \\
\text { No. }\end{array}$} & \multirow{2}{*}{$\begin{array}{l}\text { Hos- } \\
\text { pital } \\
\text { No. }\end{array}$} & \multirow{2}{*}{ Name } & \multirow{2}{*}{ Date } & \multirow{2}{*}{$\begin{array}{c}\text { Sur. } \\
\text { face } \\
\text { Area, } \\
\text { Square } \\
\text { Meters }\end{array}$} & \multirow{2}{*}{$\begin{array}{c}\text { Vital } \\
\text { Capac- } \\
\text { ity, } \\
\text { C.c. }\end{array}$} & \multirow{2}{*}{$\begin{array}{c}\text { Vital } \\
\text { Oapac- } \\
\text { ity, } \\
\text { per } \\
\text { Cent. } \\
\text { of } \\
\text { Normal }\end{array}$} & \multirow{2}{*}{$\begin{array}{c}\mathrm{CO}_{2} \\
\text { Tension, } \\
\mathrm{Mm} .\end{array}$} & \multirow{2}{*}{$\begin{array}{c}\text { Number } \\
\text { of } \\
\text { Periods }\end{array}$} & \multicolumn{2}{|c|}{$\begin{array}{c}\text { Analysis of Ex- } \\
\text { pired Air }\end{array}$} & \multirow{2}{*}{\begin{tabular}{|c}
$\mathrm{CO}_{2}$ \\
Pro- \\
duc- \\
tion \\
per \\
Minute, \\
C.c.
\end{tabular}} & \multirow{2}{*}{$\begin{array}{c}\mathrm{CO}_{2} \\
\text { Con- } \\
\text { sump- } \\
\text { tion } \\
\text { per } \\
\text { Minute } \\
\text { C.c. }\end{array}$} \\
\hline & & & & & & & & & $\mathrm{CO}_{2}$ & Oxygen & & \\
\hline 1 & 4800 & W. B. & $7 / 11 / 16$ & 1.73 & 4,710 & 98 & $\ldots$ & 3 & 3.17 & 17.52 & 189 & 209 \\
\hline 2 & 4724 & G. G. S. & $6 / 29 / 16$ & 1.55 & ..... & .. & $\ldots$ & 2 & 3.24 & 17.09 & 183 & 229 \\
\hline 3 & 4303 & M. C. & $3 / 21 / 16$ & 1.98 & 3,750 & 94 & $\ldots$ & 3 & 4.15 & 15.69 & 227 & 304 \\
\hline 4 & 4837 & M. K. & $7 / 7 / 16$ & 1.94 & 3,700 & 93 & $\ldots$ & 2 & 2.72 & 17.57 & 184 & 225 \\
\hline 5 & 4295 & H. F. T. & $3 / 23 / 16$ & 1.59 & 3,770 & 79 & $\ldots$ & 2 & 4.01 & 16.58 & 198 & 221 \\
\hline 6 & 4110 & J. C. & $2 / 18 / 16$ & 1.65 & 3,170 & 79 & $\ldots$. & 2 & 3.98 & 16.22 & 202 & 252 \\
\hline 7 & 4140 & o. G. & $2 / 21 / 16$ & 1.70 & 3,700 & 77 & $\ldots$ & 2 & 3.38 & 17.36 & 208 & 221 \\
\hline 8 & 5612 & S. G. B. & $11 / 17 / 16$ & 1.64 & 2,750 & 69 & $\ldots$ & 3 & 2.70 & 17.50 & 149 & 202 \\
\hline 9 & 5576 & W. H. T. & $11 / 11 / 16$ & 1.69 & 2,600 & 65 & $\ldots$ & 3 & 2.80 & 17.66 & 190 & 234 \\
\hline 10 & 4258 & W. A. & $3 / 7 / 16$ & 1.71 & 3,050 & 64 & $\ldots$ & 2 & 3.36 & 17.04 & 230 & 280 \\
\hline \multicolumn{2}{|c|}{ Average... } & .. & ......... & 1.72 & 3,467 & .. & .... & $\ldots$ & 3.35 & 17.04 & 196 & 238 \\
\hline 11 & 4373 & J. J. MeN. & $3 / 28 / 16$ & 1.96 & 2,410 & 60 & $\ldots$ & 3 & 2.77 & 17.51 & 207 & 271 \\
\hline 12 & 4151 & W. E. J. & $2 / 14 / 16$ & 1.57 & 2,280 & 57 & $\ldots$. & 3 & 2.17 & 18.50 & 194 & 227 \\
\hline 13 & 4766 & T. W. D & $6 / 28 / 16$ & 1.69 & 2,200 & 55 & $39.7^{*}$ & 3 & 2.37 & 18.26 & 193 & 228 \\
\hline 14 & 4262 & G. A. I. & $3 / 14 / 16$ & 1.53 & 2,080 & 52 & $\ldots .$. & 3 & 2.83 & 17.46 & 158 & 206 \\
\hline 15 & 4963 & F. W. B. & $7 / 12 / 16$ & 2.08 & 2,050 & 51 & $35.3+\S$ & 2 & 2.44 & 17.87 & 238 & 321 \\
\hline 16 & 4414 & s. B. & $3 / 30 / 16$ & 1.71 & 1,980 & 50 & $\cdots$ & 2 & 2.42 & 18.07 & 192 & 241 \\
\hline 17 & 4264 & C. G. & $4 / 11 / 16$ & 1.90 & 2,300 & 45 & $\ldots$ & 2 & 2.51 & 17.85 & 168 & 220 \\
\hline 18 & 4275 & G. G. & $3 / 10 / 16$ & 1.96 & 2,120 & 44 & $\ldots$. & 2 & 2.31 & 18.10 & 230 & 302 \\
\hline 19 & 5795 & M. F, M. & $12 / 19 / 16$ & 2.14 & 2,100 & 44 & $\left\{30.6^{*}\right.$ & 3 & 2.99 & 17.16 & 239 & 323 \\
\hline 20 & 4411 & M. $\mathbf{M}$. & 4/ $4 / 16$ & 1.75 & 1,990 & 42 & $\ldots$. & 2 & 2.75 & 17.52 & 210 & 277 \\
\hline 21 & 4796 & H. B. & 7/ $3 / 16$ & 1.71 & 1,950 & 41 & $\ldots$. & 3 & 2.59 & 18.02 & 198 & 232 \\
\hline 22 & 5740 & R. G. & 12/ $9 / 16$ & 1.56 & 1,640 & 41 & $30.4^{*}$ & 1 & 2.02 & 18.43 & 175 & 233 \\
\hline 23 & 5704 & C. $\mathbf{N}$. & $12 / 7 / 16$ & 1.57 & 1,475 & 37 & $30.4^{*}$ & $\mathbf{1}$ & 1.91 & 18.80 & 221 & 259 \\
\hline 24 & 4262 & G. A. I. & $3 / 2 / 16$ & 1.70 & 1,200 & 30 & $30.4+\|$ & 2 & 2.08 & 18.51 & 236 & 291 \\
\hline & age & & & 1.77 & 1,984 & .. & $\ldots$. & $\cdots$ & 2.44 & 18.00 & 206 & 259 \\
\hline
\end{tabular}

* Carbon dioxid tension in alveolar air.

+ Carbon dioxid tension in blood (Van slyke method).

'These carbon dioxid determinations were made on June 4, 1916.

Blood carbon dioxid taken on July 4 , 1916 .

$\|$ Blood carbon dioxid taken on March 4, 1916. Vital capacity had risen on this date to 1,470 c.c. (37.6 per cent.). 


\section{Determinations}

\begin{tabular}{|c|c|c|c|c|c|c|}
\hline $\begin{array}{l}\text { Respira- } \\
\text { tory } \\
\text { Quotient }\end{array}$ & $\begin{array}{c}\text { Calories } \\
\text { per } \\
\text { Square } \\
\text { Meter } \\
\text { per } \\
\text { Hour }\end{array}$ & $\begin{array}{l}\text { Metabo- } \\
\text { lism } \\
\text { in } \\
\text { per } \\
\text { Cent. } \\
\text { of } \\
\text { Normal }\end{array}$ & $\begin{array}{l}\text { Minute- } \\
\text { Volume, } \\
\text { Liters }\end{array}$ & $\begin{array}{c}\text { Rate of } \\
\text { Respira- } \\
\text { tion } \\
\text { per } \\
\text { Minute }\end{array}$ & $\begin{array}{c}\text { Aver- } \\
\text { age } \\
\text { Volume } \\
\text { of } \\
\text { Single } \\
\text { Respira- } \\
\text { tior }\end{array}$ & Diagnosis \\
\hline 0.904 & 35.7 & 10 & 6.03 & 12.7 & 475 & $\begin{array}{l}\text { Acute articular rheumatism; mitral insufficiency (?); no } \\
\text { symptoms referable to heart }\end{array}$ \\
\hline 0.799 & 42.6 & $7+$ & 5.71 & 13.4 & 426 & $\begin{array}{l}\text { Acute articular rheumatism; mitral insufficiency; heart com- } \\
\text { pletely compensated }\end{array}$ \\
\hline 0.747 & 43.7 & $10+$ & 5.52 & 9.0 & 639 & $\begin{array}{l}\text { Chronic myocarditis; aortic insuffeiency; mitral insufficiency } \\
\text { and stenosis; recovering from decompensation; no dysp- } \\
\text { nea while in bed }\end{array}$ \\
\hline 0.818 & 33.6 & $5-$ & 6.85 & 16.3 & 422 & $\begin{array}{l}\text { Chronic nephritis; chronic myocarditis and auricular fibril- } \\
\text { lation; about to be discharged after recovery from } \\
\text { decompensation }\end{array}$ \\
\hline 0.895 & 44.1 & $7 \cdots$ & 4.99 & 10.3 & 457 & $\begin{array}{l}\text { Acute articular rheumatism; acute serofibrinous pleurisy; } \\
\text { chronic myocarditis; slight signs of cardiac insufficiency }\end{array}$ \\
\hline 0.802 & 44.0 & $11+$ & 5.12 & 8.8 & 581 & $\begin{array}{l}\text { Mitral stenosis and insufficiency; auricular fibrillation: } \\
\text { chronic arthritis; no evidence of cardiac insuffeiency }\end{array}$ \\
\hline 0.919 & 38.6 & $3-$ & 6.07 & 15.2 & 400 & $\begin{array}{l}\text { Mitral stenosis and insufficiency; auricular fibrillation: } \\
\text { has recovered from an attack of decompensation and } \\
\text { is about to be discharged from the hospital }\end{array}$ \\
\hline 0.738 & 35.0 & $0+$ & 5.58 & 16.4 & 342 & $\begin{array}{l}\text { Chronic nephritis; chronic myocarditis and auricular fibril- } \\
\text { lation; moderately decompensated heart; walked to } \\
\text { hospital on day before this observation }\end{array}$ \\
\hline 0.812 & 40.0 & $1+$ & 6.87 & 17.6 & 392 & $\begin{array}{l}\text { Chronic nephritis with hypertension: chronic myocarditis } \\
\text { with slight cardiac insuffeiency; no dyspnea except on } \\
\text { exertion }\end{array}$ \\
\hline 0.821 & 47.4 & $19+$ & 6.91 & 12.0 & 574 & $\begin{array}{l}\text { Aortic insufficiency; mitral insufficiency; heart well com- } \\
\text { pensated }\end{array}$ \\
\hline 0.826 & $\cdots$ & $2.5+$ & 5.97 & 13.17 & 471 & \\
\hline 0.764 & 39.4 & $12+$ & 7.55 & 22.1 & 354 & $\begin{array}{l}\text { Chronic nephritis with hypertension; chronic myocarditis; } \\
\text { recovering from acute attack of cardiac insuffeciency; no } \\
\text { dyspnea while in bed }\end{array}$ \\
\hline 0.855 & 42.3 & $4-$ & 9.07 & 26.3 & 346 & $\begin{array}{l}\text { Mitral stenosis and insuffciency; three days after entering } \\
\text { hospital with acute bronchitis; dyspnea on slght exertion: } \\
\text { made a rapid recovery }\end{array}$ \\
\hline 0.847 & 39.4 & $1-$ & 8.27 & 22.1 & 375 & $\begin{array}{l}\text { Mitrai stenosis and insuffeiency; auricular fibrillation; } \\
\text { recovering from acute attack of cardiac insufficiency }\end{array}$ \\
\hline 0.767 & 38.5 & $9+$ & 5.65 & 15.5 & 341 & $\begin{array}{l}\text { Chronic neplaritis with hypertension; chronic myocarditis; } \\
\text { recovering from acute decompensation; no dyspnea while } \\
\text { in bed }\end{array}$ \\
\hline 0.741 & 44.9 & $27+$ & 9.91 & 21.2 & 469 & $\begin{array}{l}\text { Chronic nephritis with hypertension; chronic myocarditis; } \\
\text { acutely decompensated heart; much edema }\end{array}$ \\
\hline 0.797 & 40.6 & $2+$ & 8.10 & 27.0 & 308 & $\begin{array}{l}\text { Chronic nephritis; syphilite aortitis and aortic insufficiency; } \\
\text { moderately severe decompensation }\end{array}$ \\
\hline 0.764 & 33.0 & $6-$ & 6.78 & 19.0 & 355 & $\begin{array}{l}\text { Chronic nephritis and hypertension; syphilitic aortitis and } \\
\text { aortic insufficiency; recovered from severe decompensation; } \\
\text { no dyspnea on walking slowly }\end{array}$ \\
\hline 0.762 & 43.9 & $25+$ & 10.10 & 22.0 & 479 & $\begin{array}{l}\text { Chronic nephritis and hypertension; chronic myocarditis; } \\
\text { acutely decompensated with considerable dyspnea }\end{array}$ \\
\hline 0.744 & 42.8 & $22+$ & 8.11 & 13.2 & 651 & $\begin{array}{l}\text { Chronic myocarditis and auricular fbrillation; acutely } \\
\text { decompensated }\end{array}$ \\
\hline 0.758 & 45.1 & $14+$ & 7.69 & 18.1 & 428 & $\begin{array}{l}\text { Chronic nephritis and hypertension; mitral stenosis and } \\
\text { insufficiency; auricular flbrillation; acutely decompensated }\end{array}$ \\
\hline 0.854 & 39.4 & $3-$ & 7.76 & 20.1 & 386 & $\begin{array}{l}\text { Aortic insuffiency; mitral insufficiency recovering from } \\
\text { severe attack of decompensation; no dyspnea while at rest }\end{array}$ \\
\hline 0.751 & 42.5 & $21+$ & 8.81 & 25.5 & 346 & $\begin{array}{l}\text { Chronic myocarditis and auricular fibrillation; acutely } \\
\text { decompensated }\end{array}$ \\
\hline 0.853 & 48.1 & $21+$ & 11.80 & 25.4 & 465 & $\begin{array}{l}\text { Chronic nephritis and hypertension; chronic myocarditis; } \\
\text { acutely decompensated }\end{array}$ \\
\hline 0.811 & 49.4 & $40+$ & 11.60 & 27.9 & 413 & $\begin{array}{l}\text { Chronic nephritis and hypertension; chronic myocarditis; } \\
\text { acutely decompensated }\end{array}$ \\
\hline 0.791 & $\cdots$ & $12.8+$ & 8.59 & 21.8 & 408 & \\
\hline
\end{tabular}


Carbon Dioxid Production and Orygen Consumption.-In spite of the difference in the analyses of the expired air the actual production of carbon dioxid and consumption of oxygen per minute does not vary markedly in the two groups of patients. Both carbon dioxid production and oxygen consumption, however, and especially the latter, are somewhat higher in Group II, in which the expired air showed the lower carbon dioxid and the higher oxygen percentages.

Respiratory Quotient.-The respiratory quotients are normal in both groups of cases. The slightly lower quotient (0.79) in Group II corresponds to the higher consumption of oxygen in this group.

Basal Metabolism.-In Group I the metabolism averaged only 2.5 per cent. above the normal figure, and in only one instance (Case 10) was it essentially abnormal. The average metabolism in Group II was approximately 13 per cent. above normal, thus barely above the extreme limits usually set for the normal. Six patients in this group had metabolism of more than 20 per cent. above normal. These determinations of the basal metabolism agree satisfactorily with the results already referred to which were obtained with the large bed calorimeter at the Russell Sage Institute of Pathology. The patients who were in the best general condition (Group I) showed with one exception (Case 10) an essentially normal metabolism, while in the more severely decompensated patients the metabolism was sometimes normal, and sometimes considerably above the normal.

Minute-Volume of Air Breathed.-There is a rather striking difference in the minute-volume of air breathed by the two groups of patients. In Group I the minute-volume averaged about 6 liters, while in Group II it was slightly more than 8.5 liters. There is a general tendency for the minute-volume to be higher in the more severely decompensated members of Group II, in whom the vital capacity is lowest, but this relationship is somewhat obscured by the variation in size of the individual members of the group. G. A. L. was studied twice, first (Case 24) when he was severely decompensated, and later (Case 14) when he was in comparatively good condition and was quite comfortable while at rest. Between these two observations his vital capacity rose from 1,200 c.c. to 2,080 c.c., and his minute-volume fell from 11.6 liters to 5.65 liters, a drop of about 100 per cent. At the same time the basal metabolism showed a decrease of 31 per cent. It would, of course, be natural to associate the high minute-volume in the cases in Group II with an increase of metabolism, but scrutiny of the individual cases shows that such an association does not exist, and a comparison of the average results in the two groups of cases shows that the rise of the minute-volume in Group II is much more definite than is the rise of metabolism. In a few cases the low carbon dioxid 
of the alveolar air or blood is evidence of an acidosis, but this is not of sufficiently high grade to account for the rise in minute-volume satisfactorily. This high minute-volume in severely affected cardiac patients has been observed by numerous other investigators among whom may be mentioned Beddard and Pembrey. ${ }^{10}$

Rate of Respiration.-As would be naturally expected, the rate of respiration is considerably higher in the patients whose clinical condition was worst. In Group II the average rate was 21.8, and in Group I it was only 13.2 per minute.

Volume per Respiration.-There is a definite difference between the two groups in the depth of respiration. In Group I the average volume per respiration was 471 c.c., while in Group II it was 408 c.c. Thus the respiration of the subjects of Group II was more rapid and more shallow than it was in the members of Group I.

\section{SUMMARY AND DISCUSSION}

Studies of the gaseous metabolism have been made in two group: of patients with heart disease. The subjects of Group I were in good or fairly good clinical condition, while those in Group II were for the most part more severely affected, being either decompensated and dyspneic while at rest in bed or becoming dyspneic on slight exertion. The basal metabolism was slightly higher in the patients of Group II. In some subjects of Group II the increase of metabolism was considerable, but this increase was not constant for all members of the group, and the average heat production per square meter of body surface was scarcely above the normal. On the other hand the minutevolume of air breathed averaged approximately 30 per cent. higher in Group II than it did in Group I, and individual instances were at least double the normal. Closely related to this are other observations which show that in the more seriously sick patients of Group II the rate of respiration is higher, the average volume of respiration is less, and the composition of the expired air approaches more closely to that of atmospheric air than was the case in Group I.

How are these abnormalities in the volume and composition of the expired air to be interpreted? Siebeck ${ }^{9}$ has made experiments which have a direct bearing on this subject, and which he explains on the basis that the inspired air is not thoroughly mixed with the alveolar air. Bronchitis, edema, areas of atelectasis, etc., prevent a complete diffusion of the inspired air throughout the lung, so that the efficiency of the respiration is decreased and the inspired air is less completely used than normally. This shows itself in the fact that the expired air

10. Beddard and Pembrey: Brit. Med. Jour., 1908, 2, 580. 
has a high content of the inspired hydrogen in Siebeck's experiments and of oxygen in our own observations. In order, then, to obtain a sufficient amount of oxygen to supply the needs of the metabolism, a larger volume of air must be breathed. It is quite possible that an imperfect mixing or diffusion of the inspired air is a factor in the explanation of these observations, and it is easy to comprehend that such a condition may be present, but there is another feature that appears to be important. The two sets of patients whom we have studied were grouped according to the vital capacity of the lungs, those in Group I having a vital capacity of over 60 per cent., and those in Group II of 60 per cent. or less of our normal standards. Careful study of the minute-volume of the two groups of subjects shows a definite relation between this and the vital capacity of the lungs. In general, as the vital capacity falls, the minute-volume rises. There is, however, no distinct increase in the minute-volume until the vital capacity dropped to 60 per cent. or less of the standards which we have adopted as.normal. If the vital capacity is below 60 per cent., the minute-volume is almost invariably increased. Case 14 is an apparent exception to this, but it is explained by the fact that G. A. L . is a small frail man, and the normal standard to which his vital capacity was referred is probably too high. His clinical condition was much better than has been the case with most patients having a vital capacity of only 52 per cent. of the normal, and he can fairly be considered an instance where the comparison of persons to general normal standards leads to an erroneous conception. Such exceptions are, of course. bound to occur.

In general, however, if the vital capacity is as low as 60 per cent. of the normal or less, the minute-volume of air breathed is above normal. Such a decrease in the vital capacity is considerable and is found usually only in rather severely affected patients. Many of the patients had obvious collections of fluid in the pleural cavities, or there was evidence of congestion and edema over the lower portions of the lungs behind, so that the available respiratory surface of the lungs was much diminished. For purposes of comparison with this group a patient may be mentioned with a pleural effusion which apparently filled one side of the chest so that one whole lung was practically completely thrown out. His vital capacity was 48 per cent. It does not seem illogical to assume that in these patients of Group II with much decreased vital capacity the respiratory surface is similarly diminished. The "dead space," however - nasopharynx, oropharynx, trachea, large bronchi, etc. - in which there is no respiratory exchange, probably remains essentially unchanged. The volume of each respiration is less than normal ( 408 c.c. in Group II as opposed to 471 c.c. 
in Group I), but the dead space being unchanged, a much smaller proportion of each respiration reaches the alveoli. In order, however. that a normal or slightly higher than normai amount of oxygen shall be taken up by the blood in the alveolar walls, so as to keep pace with the metabolism of the body, the rate of respiration is increased. The expired air contains less carbon dioxid and more oxygen than normal, because it contains a larger proportion of air from the dead space.

The various abnormal findings in patients with severe heart disease can thus be explained on the basis of a decrease in the vital capacity of the lungs associated with a diminished respiratory surface. The volume per respiration is decreased, but the dead space is probably unchanged, so that the proportion of each inspiration remaining in the dead space is relatively increased. Oxygen supply is kept up by raising the rate of respiration, and in order that the alveolar ventilation may remain sufficient in spite of the relative increase of "dead space" the minute-volume of air breathed must be increased.

These observations on the increased minute-volume in patients with severe heart disease have a practical bearing on the production of dyspnea. If a normal person walks at a moderate pace the metabolism rises and the minute-volume is increased perhaps fourfold. With a patient in Group I it might thus rise from 6 to 24 liters. This is not a large amount, and a person with a normal vital capacity who can increase the depth of respiration easily would have no discomfort on breathing such a volume. If, however, one of the patients in Group II performed similar exercise, the minute-volume in his case, likewise rising fourfold, would amount to over 34 liters. This is much higher than it was with the more normal subject of Group I, and it thus is more difficult to maintain. It is, moreover, especially difficult for the subject in Group II, for his vital capacity is low and he cannot breathe deeply. It will thus be seen that the lower the minute-volume of air breathed at rest the less will be the tendency to dyspnea on exertion and the greater will be the patient's reserve. In like manner the slower the rate of respiration at rest, the greater will be the reserve. Thus an increase of the minute-volume of air breathed while at rest, and an increase in the rate of respiration while at rest, may both be factors in the production of dyspnea in heart disease.

\section{CONCLUSIONS}

Observations are reported on the gaseous metabolism and pulmonary ventilation of two groups of patients with heart disease. Group I consists of subjects in good or fairly good condition, in whom the vital capacity of the lungs was over 60 per cent. of the normal. Group 
II consists of much more severely affected patients in whom the vital capacity was 60 per cent. of the normal or less.

The basal metabolism calculated from the oxygen consumption per square meter of body surface averaged 2.5 per cent. above normal in Group I, and 12.8 per cent. above normal in Group II.

The average volume per respiration was less in Group II than in Group I, and the average rate of respiration was higher in Group II than in Group I.

The minute-volume of air breathed averaged approximately 30 per cent. higher in the members of Group II than it did in those of Group I.

The relation is pointed out between the increase of the minutevolume of the more seriously affected patients and the decrease in the vital capacity of the lungs.

Finally it is shown that this high minute-volume is a factor in the production of dyspnea in persons with severe heart disease. 